\title{
EL TRATAMIENTO NEOPRAGMATISTA DE LA VERDAD EN RICHARD RORTY
}

\section{NEOPRAGMATIST TREATMENT OF TRUTH IN RICHARD RORTY}

\author{
José ANTONIO GaRCÍA-LORENTE* \\ Università degli Studi di Padova
}

Resumen: Richard Rorty, uno de los autores más influyentes en la actualidad, elabora una crítica al concepto filosófico de verdad como correspondencia. La conclusión del neopragmatismo de Rorty es que la idea de la verdad como correspondencia entre el lenguaje y los hechos no puede hacerse efectiva porque ya no funciona. La concepción neopragmatista de la verdad señala los únicos usos del término verdadero, centrándose en la idea de la justificación. En este trabajo se presenta la concepción neopragmatista de la verdad, para analizar la propia consistencia interna del neopragmatismo respecto a la noción filosófica de verdad.

PALABRAS ClaVE: Richard Rorty, neopragmatismo, verdad.

ABSTRACT: Richard Rorty, one of the most influential authors of our time, presents a critique of the philosophical concept of truth as correspondence. The conclusion of Rorty's neopragmatism is that the idea of truth as correspondence between language and facts is ineffective because it no longer works. The neopragmatist conception of truth indicates the only possible uses for the term «truthful,» revolving around the idea of justification. In this article, the neopragmatist notion of truth is presented in order to

* Doctor europeo en Filosofía por la Universidad de Murcia, becario posdoctoral en el Departamento de Filosofía de la Università degli Studi di Padova, Italia. E-mail: jogarlo@um.es.

Este trabajo ha sido posible realizarlo gracias a una beca de formación posdoctoral del Programa Séneca 2009, integrada en el Plan de Ciencia y Tecnología de la Región de Murcia 20072010, y se inserta en el marco del Proyecto de investigación «La metafísica tras la superación posmoderna de la metafísica» (FFI2008-05782/FISO) financiado por el Ministerio de Ciencia e Innovación. 
analyse neopragmatism's own internal consistency with respect to the philosophical notion of truth.

KEYWORDS: Richard Rorty, neopragmatism, truth.

\section{La interpretación rortyana de la verdad como correspondencia}

Rorty considera que la noción de verdad como correspondencia con la realidad ha adquirido una nueva relevancia, sobre todo a partir de los debates entre realistas y antirrealistas en el ámbito de la filosofía analítica del siglo XX. En este contexto contemporáneo, el lenguaje ha sustituido a la mente como aquello que está frente a la realidad. En la Introducción a su Consequences of Pragmatism, Rorty divide a los defensores de la teoría de la verdad como correspondencia en dos grupos, dependiendo de una cierta comprensión del realismo. Por un lado, se encuentran «los realistas técnicos»: los filósofos del lenguaje, que se sirven de las tesis de Kripke acerca de la referencia (Hartry Field, Richard Boyd, y, en ocasiones, Hilary Putnam) para defender una epistemología realista; por otro lado, «los realistas intuitivos»: los que creen que existen hechos que se encuentran fuera del alcance de los conceptos humanos, ya que no se pueden verificar (Cavell, Nagel, Thompson Clarke y Berry Stroud) ${ }^{1}$.

El realista técnico, nos dice Rorty, concibe el mundo como algo que está previamente dividido en géneros naturales de particulares con sus rasgos esenciales y accidentales. Según esto, la cuestión sobre la verdad de "X es f» se resuelve descubriendo cuál es la referencia de «X» (un hecho físico) y a continuación se descubre si ese particular o ese género es $\mathrm{f}$. Esta es una teoría fisicalista de la referencia y con ella el realista técnico defiende una la teoría de

\footnotetext{
${ }^{1}$ Rorty, R., «Introducción» en Consequences of Pragmatism (Essays: 1972-1980), University of Minnesota Press, Minneapolis 1982. Traducción al español: Consecuencias del pragmatismo, Tecnos, Madrid 1996, pp. 29-50. (Comillas del autor). Cito como CP. Para las citas de las obras de Rorty utilizo las traducciones al español. En alguna ocasión, modifico la traducción para ceñirme mejor al texto original. La primera vez que se cita una obra de este autor se dan los datos completos y posteriormente se utilizan las abreviaturas habitualmente empleadas cuando se citan, indicando la página de la edición española.
} 
«la verdad como correspondencia con la realidad», que puede ser formulada como la correspondencia entre el lenguaje y el modo de ser de las cosas en sí mismas $^{2}$. Con esta teoría, el realista considera que es posible emparejar las partes del mundo con las partes de nuestras creencias u oraciones de tal modo que las relaciones entre estas últimas encajan con las relaciones entre las primeras $^{3}$. El realista intuitivo, por su parte, parte de la intuición de que nuestro entendimiento tiene límites y, por tanto, nuestro lenguaje también. Según esto, el realista intuitivo defiende que hay hechos que no pueden expresarse en el lenguaje y, por tanto, la realidad es algo inefable, algo que no se puede aprehender creyendo proposiciones verdaderas. En este caso, la verdad es entendida en un sentido metafísico, ya que el realista cree que existe algo tal como la verdad Filosófica: «Algo que no es tan sólo un texto más, sino algo a lo que los distintos textos intentan "ajustarse" ${ }^{4}$.

El propio Rorty, en el ensayo "The World Well Lost», explica la visión del mundo, desde el punto de vista del realista. Para Rorty, el mundo es para el realista un «être-en-soi sólido, indómito y yerto que se mantiene a distancia y que muestra una sublime indiferencia aunque lo colmemos de atenciones» ${ }^{5}$. Bajo la perspectiva del realista, el mundo es concebido como algo totalmente independiente del conocimiento, pues incluye algo que va más allá de «cualquier referente asignable a la gran mayoría de nuestras creencias» ${ }^{6}$. Tanto es así, que la verdadera realidad podría carecer manifiestamente de cosas a las que normalmente nos referimos. Según Rorty, el realista no tendría ningún inconveniente en asumir que «todas las cosas a las que nos referimos podrían ser completamente distintas de lo que pensamos», puesto que (valga el ejemplo) "podríamos estar equivocados en lo referente a la naturaleza de las estrellas» ${ }^{7}$. Rorty nos dice que esta noción de «mundo» es equiparable a los átomos, al vacío o a la cosa-en-sí kantiana: algo que ni tiene ni admite especificación algu-

${ }^{2}$ Cfr. Rorty, R., «Introducción» en CP, pp. 29-41.

${ }^{3}$ Cfr. Rorty, R., "John Searle en torno al realismo y el relativismo» en Truth and Progress (Philosophical Papers, Volume 3), Cambridge University Press, Cambridge 1998. Traducción al español: Verdad y progreso (Escritos filosóficos 3), Paidós, Barcelona 2000, p. 103. Cito como TP.

${ }^{4}$ Rorty, R., «Introducción» en $C P$, p. 50. (Comillas del autor).

${ }^{5}$ Rorty, R., «El mundo felizmente perdido» en $C P$., p. 73.

${ }^{6}$ Rorty, R., «El mundo felizmente perdido» en CP., p. 74.

${ }^{7}$ Rorty, R., «El mundo felizmente perdido» en CP., p. 75. 
na, porque cree que, además del mundo, existe algo ahí fuera llamado «la verdad del mundo» ${ }^{8}$.

Según Rorty, los realistas defienden la existencia de la verdad del mundo, recurriendo a la idea de la verdad como correspondencia: «Una relación de "correspondencia» entre determinadas oraciones (muchas de las cuales, sin duda alguna, están por formular) y el mundo mismo» ${ }^{9}$. Esta noción de la verdad como correspondencia es desarrollada por Rorty en los artículos que forman parte de Objectivity, relativism and truth, explicitada como teoría representacionista. Los representacionistas son, según Rorty, aquellos filósofos que se cuestionan sobre qué enunciados se encuentran de modo representacional o de correspondencia con elementos no lingüísticos, considerando que la mente o el lenguaje contiene representaciones de la realidad. Los defensores de una teoría representacionista sostienen la posibilidad de la correspondencia entre lenguaje y realidad, donde «el elemento no lingüístico que hace verdadero a $S$ es el que representa $S_{{ }^{10}}{ }^{0}$. El representacionista considera que conseguimos una representación precisa, porque, en ocasiones, los elementos nolingüísticos hacen que los elementos lingüísticos se utilicen de la manera en que se utilizan. Por ejemplo, nosotros podemos usar el término «átomo», porque, como indica Rorty, los representacionistas creen que existe realmente átomos ahí fuera, que se han «hecho representar de forma más o menos precisa» ${ }^{11}$.

\section{2. la crítica de Rorty a la verdad como correspondencia}

La crítica del realismo constituye el inicio del argumento de Rorty contra la noción de verdad como correspondencia. Rorty considera que no hay que confundir «la trivialidad de que el mundo puede hacer que tengamos razón al creer que una proposición es verdadera, con la afirmación de que el mundo, por su

${ }^{8}$ Cfr. Rorty, R., «El mundo felizmente perdido» en CP., pp. 73-75.

${ }^{9}$ Rorty, R., «Introducción» en CP, pp. 35-36.

${ }^{10}$ Rorty, R., «Introducción» en Objectivity Relativism, and Truth (Philosophical Papers, Volume 1), Cambridge University Press, Cambridge 1991. Traducción al español: Objetividad, relativismo y verdad, Paidós, Barcelona 1996, p. 19. Cito como ORT.

${ }^{11}$ Rorty, R., «Introducción» en $O R T$, p. 20. 
propia iniciativa, se descompone en trozos, con la forma de proposiciones, llamados «hechos» ${ }^{12}$. Por esta razón, la falacia de la teoría de la verdad como correspondencia comienza cuando se piensa que la relación entre el lenguaje y la realidad es fragmentaria («como la relación entre piedras individuales y rocas individuales») $)^{13}$.

La verdad como correspondencia con la realidad — nos dice Rorty- es «una metáfora que no se puede hacer efectiva». En algunos enunciados como «Júpiter tiene satélites» o "el gato juega con el zapato» sí es posible afirmar que existe "un isomorfismo entre las partes de las oraciones verdaderas debidamente analizadas y las partes del mundo con ellas emparejadas» ${ }^{14}$. Sin embargo, en la mayoría de los enunciados verdaderos como «el gato no juega con el zapato», «el universo es infinito» o «el placer es mejor que el dolor» no es posible aplicar una teoría de la verdad como correspondencia, pues no podemos decir que estos enunciados estén apuntando a algo de la realidad. Pero Rorty da un paso más y dice que no podríamos recuperar la noción de verdad como correspondencia aún cuando construyamos «un esquema metafísico que empareje algo del mundo con cada parte de cada enunciado verdadero y alguna relación de primer orden con toda relación metalingüística correspondiente» ${ }^{15}$. En última instancia, y, aún cuando fuese posible construir un esquema metafísico que empareje algo del mundo con cada parte de cada enunciado verdadero, «deberíamos preguntarnos si el hablar de gatos o de la bondad es la forma correcta de fragmentar el universo en trozos, si nuestro lenguaje corta la realidad por las articulaciones» ${ }^{16}$. Los antirrepresentacionistas no ven la

${ }^{12}$ Rorty, R., «La contingencia del lenguaje» en Contingency, Irony and Solidarity, Cambridge University Press, New York 1989. Traducción al español: Contingencia, ironía y solidaridad, Paidós, Barcelona 1991, p. 25. (Comillas del autor). Cito como CIS.

${ }^{13}$ Rorty, R., «Pragmatismo, Davidson y la verdad» en ORT, p. 198. Nadie habría tenido un uso de la verdad como correspondencia a no ser porque existe la concepción de que las creencias cortan la realidad en sus articulaciones, una realidad, que no es relativa a los vocabularios, es decir, la misma naturaleza (Nature's Own), independientemente de los intereses humanos. Rorty estima que sin esta imagen de cortar-por-las-articulaciones, nadie habría sugerido que la creencia verdadera es representación exacta de la realidad. Cfr. «Response to Robert Brandom» en Rorty and His Critics, Blackwell, Oxford 2000, p. 185.

${ }^{14}$ Rorty, R., «Pragmatismo, relativismo e irracionalismo» en $C P$, p. 244.

${ }^{15}$ Rorty, R., «Textos y terrones» en $O R T$, p. 115. (Cursivas del autor).

${ }^{16}$ Rorty, R., «Textos y terrones» en $O R T$, p. 115. 
manera de formular una prueba independiente (que se sitúe más allá) de la exactitud de la representación.

Rorty no tiene problema en afirmar la existencia de un dato o hecho independiente; por ejemplo, que las luces de Júpiter que Galileo divisó eran un elemento físico duro: «la resistencia física en bruto», es decir, un dato en-sí, extremadamente real. Sin embargo, Rorty no entiende cómo se puede transferir el carácter bruto del los hechos, a la verdad de las oraciones. Siguiendo a Davidson, Rorty dice que «la causación no está sujeta a descripción». Pues, si es cierto que el hecho en sí (el impacto en la retina de las luces de Júpiter) forma parte del mundo (existe realmente), a esta dureza causal hay que añadir una determinada explicación, es decir, una descripción de lo que se percibe. Por esta razón, Rorty recuerda que, a pesar de que las luces de Júpiter que Galileo divisó a través del telescopio comportaban un hecho duro, este hecho se incorporó al mundo de manera distinta. Mientras que los seguidores de Aristóteles consideraron que las luces de Júpiter eran una anomalía que tenía que ser integrada en una cosmología aristotélica, los admiradores de Galileo pensaron que esa anomalía hacía saltar en pedazos la teoría de las esferas cristalinas. Con esto se demuestra, según Rorty, que los hechos son «entidades híbridas», pues «las causas de la enunciabilidad de una oración incluyen tanto estímulos físicos como nuestra elección anterior de respuesta a estos estímulos» ${ }^{17}$.

El neopragmatismo hereda la perspectiva llevada a cabo por el giro lingüístico, en el sentido de que tanto la mente como el lenguaje penetran tan profundamente en lo que nosotros llamamos «realidad», que la idea de vernos a nosotros mismos como cartógrafos del algo, independientemente del lenguaje, queda fatalmente comprometido desde el principio. Los hechos están atravesados por el lenguaje, de modo que, cuando se trata de explicar la verdad de nuestras creencias, difícilmente se puede distinguir entre el papel de nuestra actividad descriptiva, de nuestro uso de las palabras y el papel del resto del universo ${ }^{18}$. Pensar

${ }^{17}$ Rorty, R., «Textos y terrones» en $O R T$, p. 117.

${ }^{18}$ Rorty exporta esta idea del filósofo analítico Donald Davidson en la crítica a la distinción entre esquema y contenido: «Esto significa abandonar todo intento de agrupar nuestras proposiciones en función de si lo que las «hace» verdaderas es el «mundo» o somos «nosotros», es decir, abandonar la problemática de realismo y antirrealismo». Rorty, R., "Charles Taylor en torno a la verdad» en $T P$, p. 119. 
que el mundo o la realidad se descompone en trozos o hechos brutos es un intento imposible de ver el mundo desde ninguna parte: «Un intento confuso por estar al mismo tiempo dentro y fuera del lenguaje» ${ }^{19}$. Admitir una salida del lenguaje supondría la salida de nosotros mismos, para ver cómo y de qué manera nuestro lenguaje corta o fragmenta el mundo en trozos. Este intento de los representacionistas es una perspectiva que se ha desvinculado del lenguaje y de nuestras creencias y las ha contrastado con algo sin su ayuda ${ }^{20}$.

Por todo lo dicho, el neopragmatista declara que «la noción tradicional de que «la verdad es correspondencia con la realidad» es una metáfora que no se puede hacer efectiva y está gastada ${ }^{21}$. Explicar la verdad o falsedad en términos de correspondencia o no-correspondencia con la realidad, o en términos de una relación de «acuerdos» $\mathrm{o}$ "correspondencia» entre algo humano y no humano trae «desgraciados resultados» ${ }^{22}$, ya que, «varios siglos de esfuerzos no han servido para dar un sentido digno de interés a la noción de "correspondencia» (de los pensamientos o de las palabras con las cosas) $»^{23}$. Por lo demás, el debate realismo-antirrealismo es passé, pues la sociedad está progresando hacia una concepción del lenguaje, que no es posible concebirlo en términos de correspondencia con la realidad ${ }^{24}$.

\section{La concepción neopragmatista de la verdad}

La estrategia de Rorty respecto a la noción de verdad ha ido cambiando en su trayectoria intelectual. En los años en los que redactó los ensayos que formarían parte de Consecuencias del pragmatismo, el Norteamericano rechaza cualquier teoría filosófica de la verdad, pero mantiene un tratamiento de ésta con-

\footnotetext{
${ }^{19}$ Rorty, R., «Pragmatismo, Davidson y la verdad» en $O R T$, p. 186.

${ }^{20}$ Cfr. Rorty, R., "John Searle en torno al realismo y el relativismo» en TP, p. 95. Richard Rorty recoge esta idea del también filósofo Americano Hilary Putnam en Realism with a Human Face, Harvard University Press, Cambridge (Mass.) 1990. Cfr. Rorty, R., «Introducción» en ORT, p. 22.

${ }^{21}$ Rorty, R., «Textos y terrones» en ORT, pp. 116-117.

${ }^{22}$ Cfr. Rorty, R., «Dewey, entre Hegel y Darwin» en TP, pp. 338-339.

${ }^{23}$ Rorty, R., «Introducción» en $C P$, p. 23.

${ }^{24}$ Cfr. Rorty, R., «Introduction» de Savidan, P., en What is the Use of Truth?, Columbia University Press, New York 2007, p. ix-xii.
} 
forme al pragmatista William James. En los ensayos que componen el volumen Objetivismo, relativismo y verdad incorpora la crítica davidsoniana al dualismo esquema-contenido, para mantener que «verdadero» no es un término explicativo, pero tiene un uso de aprobación o de precaución. Finalmente, en la época en la que redactó los artículos de Verdad y progreso, Rorty llega a dudar de que la verdad sea el nombre de la meta a la que debe concluir nuestra investigación y sustituye la noción de verdad por la justificación.

\section{a) El anti-esencialismo de la verdad}

En la Introducción a su Consequences of Pragmatism, Rorty tiene la intención de eliminar un tratamiento filosófico de la noción de verdad con las palabras siguientes: «Los ensayos que integran este libro tratan de extraer consecuencias de una teoría pragmatista acerca de la verdad. Esta teoría nos dice que la verdad no es la clase de cosa sobre la que quepa esperar una teoría de interés filosófico [...] todo lo que se haga en dicha área carece de interés ${ }^{25}$. Rorty aplica un antiesencialismo a la noción de verdad y considera más bien que en el vocabulario de la práctica y no de la teoría, y en el ámbito de la acción y no en el de la contemplación, es donde "podemos decir algo provechoso acerca de la verdad $»^{26}$. El neopragmatismo concibe la verdad en términos jamesianos, es decir, como «aquello cuya creencia resulta beneficiosa ${ }^{27}$, para mostrar que «de nada sirve decir que la verdad es "correspondencia con la realidad" ${ }^{28}$.

${ }^{25}$ Rorty, R., «Introducción» en CP, p. 19. En la «Introducción» de Truth and Progress, (siguiendo a Davidson) dice que «el mismo carácter absoluto de la verdad es una buena razón para pensar que «verdadero» es indefinible y que ninguna teoría de la naturaleza de la verdad es posible». Rorty, R., «Introducción» en TP, p. 14.

${ }^{26}$ Rorty, R., «Pragmatismo, relativismo e irracionalismo» en CP, p. 244.

${ }^{27}$ Esta noción de verdad procede del pragmatista clásico James y Rorty la presenta como suya en «Pragmatismo, relativismo e irracionalismo» en CP, p. 243 Esta misma definición es formulada también como: «Lo que es bueno que creamos» o «Aquello cuya creencia resulta beneficiosa» en Philosophy and the Mirror of Nature, Princeton University Press, New Jersey 1979. Traducción al español: La filosofía y el espejo de la naturaleza, Cátedra, Madrid 1983, pp. 19. 166. Cito como PMN.

${ }^{28}$ Rorty, R., "Pragmatismo, relativismo e irracionalismo» en CP, p. 243. 


\section{b) Los usos del término "verdadero»}

La estrategia que aparece en el artículo «Pragmatismo, Davidson y la verdad», para disolver los problemas tradicionales acerca de la verdad como correspondencia, consiste, según Rorty, en asumir que «verdadero» no tiene usos explicativos. En este sentido, Rorty propone una tesis negativa que consiste en disolver la problemática tradicional de la verdad afirmando que «verdadero» tiene, únicamente, los usos siguientes ${ }^{29}$ :

1. Un uso como aval o de aprobación y apoyo.

2. Un uso precautorio o de advertencia, como cuando decimos que la creencia $S$ está perfectamente justificada, pero quizás no es verdadera.

3. Un uso desentrecomillador como cuando decimos: «La nieve es blanca» es verdadero si y sólo si la nieve es blanca.

Estos usos son insertados por Rorty en los que, a su juicio, formarían parte del tratamiento pragmatista de la verdad con adhesión a las siguientes tesis ${ }^{30}$ :

1. «Verdadero no tiene usos explicativos».

2. "Comprendemos todo lo que hay que conocer sobre la relación de las creencias con el mundo cuando comprendemos sus relaciones causales con el mundo».

3. «No existen relaciones de «ser verificado» entre las creencias y el mundo».

4. "Carecen de sentido los debates realismo-antirrealismo, pues estos debates presuponen la idea vacía errónea de «verificar» las creencias».

${ }^{29}$ Cfr. Rorty, R., «Pragmatismo, Davidson y la verdad» en $O R T$, p. 175.

${ }^{30}$ Rorty, R., «Pragmatismo, Davidson y la verdad» en ORT, p. 176. Cfr. Kalpokas, D., Richard Rorty y la superación pragmatista de la epistemología, ediciones del Signo, Buenos Aires 2005, pp. 100-101. 


\section{c) Justificación versus verdad}

A partir de la sentencia del pragmatismo clásico que dice que de nada sirve entender la verdad como «la correspondencia con la realidad», Richard Rorty propone que el tratamiento de la verdad entendida como «lo bueno respecto de la creencia» o «lo que es mejor para nosotros creer» debería reemplazar más bien a «justificado» que a «verdadero»" ${ }^{31}$. En los artículos que integran el volumen Truth and Progress, la tesis fundamental de Rorty respecto a la verdad es la siguiente: "No tenemos más criterio para la verdad que la justificación», pues «el único criterio de que disponemos para aplicar la palabra «verdadero» es la justificación ${ }^{32}$. Rorty es consciente de que concebir la verdad como «lo bueno respecto de la creencia» se presta a la crítica de los que dicen que una cosa es la verdad —absoluta y eterna- y otra la justificación — transitoria y relativa-. Para escapar a esta crítica, Rorty propone abandonar cualquier intento de decir algo acerca de la verdad —al menos de la noción de verdad como correspondencia con la realidad- ya que, de acuerdo con Davidson, «la creencia humana no puede desplazarse libre de un entorno no humano» y «la mayoría de nuestras creencias (la mayoría de las creencias de cualquiera) tiene que ser verdadera ${ }^{33}$.

La distinción entre justificación y verdad, dice el Americano, no supone ninguna diferencia en la práctica. Según la premisa del pragmatismo «una diferencia debe entrañar diferencia en la práctica antes de que valga la pena discutirla ${ }^{34}$. Cuando surgen dudas respecto a la verdad de alguna creencia, sólo se pueden resolver si se buscan y se sopesan razones suplementarias en pro y en contra, es decir, hallando una justificación adecuada. Como dice Rorty: «Si tengo dudas

${ }^{31}$ Esta es la consecuencia de asumir el uso de la verdad como uso pracautorio (cautionary) y que le permite decir que la Verdad (Truth) no puede ser la meta de la investigación. Cfr. Bilgrami, A., «Is Truth a Goal of Inquiry?: Rorty and Davidson on Truth» en Rorty and His Critics, pp. 242262.

${ }^{32}$ Rorty, R., «Introducción» en TP, pp. 13. 14.

${ }^{33}$ Rorty, R., «La verdad sin correspondencia» en Philosophy and Social Hope, Penguin Books, London 1999. Traducción al español: ¿Esperanza o conocimiento? Una introducción al pragmatismo, FCE, Buenos Aires 1997, p. 24. Cfr. Rorty, R., "Response to Akeel Bilgrami» en Rorty and His Critics, pp. 262-267.

${ }^{34}$ Rorty, R., «Universalidad y verdad» en Rorty and His Critics, pp. 1-30. Traducción al español: «Universalidad y verdad» en Rorty, R./Habermas, J., Sobre la verdad: ¿validez universal o justificación?, Amorrortu, Buenos Aires 2007, p. 20. 
concretas y específicas respecto de la verdad de una de mis creencias, sólo puedo resolverlas preguntando si está adecuadamente justificada — buscando y sopesando razones suplementarias en pro y en contra- No me puedo saltar la justificación para centrar la atención en la verdad: cuando la pregunta se refiere a qué debo creer en este momento, evaluar la verdad y evaluar la justificación constituyen una misma actividad $»^{35}$. Por esta razón, el filósofo norteamericano cree estar de acuerdo con Dewey y con Davidson, en que deberíamos limitarnos a hablar de justificación o de "asertabilidad garantizada», pues hay poco que decir acerca de la verdad ${ }^{36}$.

El carácter ineludible de la justificación provoca que la verdad jamás pueda constituirse como la meta de la investigación, según el neopragmatismo. Los que creen lo contrario, nos dice Rorty, insisten en que existe una meta fija, pues «el progreso a la verdad se explica por referencia a una imagen metafísica, la de la aproximación a lo que está ahí «en cualquier caso»»" ${ }^{37}$. Para Rorty, «sólo habría una meta superior de la indagación, llamada «verdad», si hubiera una cosa tal como la justificación última, una justificación ante Dios o ante el tribunal de la razón, en tanto distintos de cualquier audiencia meramente finita ${ }^{38}$. La posibilidad de alcanzar una justificación última de cualquier creencia, sería la que nos permitiese colocarnos en «la perspectiva del ojo de Dios». Ésta sería una perspectiva exterior, que nos permitiera salir de nosotros mismos o como especifica Rorty: «La que tomara en cuenta todas las alternativas a una creencia dada y conocer todo lo que fuera pertinente para criticar cada una de esas alternativas [...] una perspectiva que tomara en cuenta no sólo todos los rasgos del mundo en tanto descrito por un conjunto dado de términos, sino cada rasgo desde toda otra des-

\footnotetext{
${ }^{35}$ Rorty, R., «¿Es la verdad una meta de la investigación? Donald Davidson versus Crispin Wright» en TP, p. 31.

${ }^{36}$ Cfr. Rorty, R., «La verdad sin correspondencia» en ¿Esperanza o conocimiento?, pp. 22-23. Los pragmatistas piensan que el intento de conexionar la justificación y la verdad procede del Teeteto de Platón. En este diálogo se afirma que para que halla conocimiento, la creencia ha de ser verdadera y estar justificada. Según Rorty, los filósofos han intentado decir algo interesante sobre la verdad o la justificación, de modo que cuanto más justificada esté una creencia resulta más verosímil que sea verdadera. Ver Rorty, R., "La verdad sin correspondencia» en ¿Esperanza o conocimiento?, pp. 28-31.

${ }^{37}$ Rorty, R., «¿Es la verdad una meta de la investigación?» en TP, p. 57. (Cursivas y comillas del autor).

${ }^{38}$ Rorty, R., «La verdad sin correspondencia» en ¿Esperanza o conocimiento?, p. 35. (Cursivas y comillas del autor).
} 
cripción posible» ${ }^{39}$. Esta perspectiva podría darse, según Rorty, pero no encontramos una buena razón para pensar eso, y, por lo tanto, no tendría mucho sentido afirmar tal cosa. En cualquier caso, como dice Rorty: «Dado que nadie conoce el futuro, que nadie sabe qué creencias permanecerán o no justificadas, no hay nada ahistórico que decir acerca del conocimiento o de la verdad $»^{40}$.

El único criterio del que se dispone para aplicar la palabra verdadero es la justificación. La justificación es siempre relativa a un auditorio, y, por tanto, hay que considerarla siempre local. Esta posición es una vía alternativa al relativismo y es denominada por Rorty como «etnocentrismo». Lo que caracteriza al etnocentrismo es «la concepción de que no puede decirse nada sobre la verdad o racionalidad aparte de las descripciones de los procedimientos de justificación conocidos que una determinada sociedad — la nuestra — utiliza en uno u otro ámbito de indagación» ${ }^{41}$. En este sentido, para el neopragmatismo: «Decir que la verdad es nuestra meta es decir meramente algo así como: esperamos justificar nuestra creencia ante tantos y tan amplios auditorios como sea posible» ${ }^{42}$. El concepto de verdad, para Rorty, puede ser utilizado - a pesar de que no se ofrezca una teoría sobre la naturaleza de la verdad - en un sentido tal como: «Tus argumentos satisfacen todas nuestras normas y estándares actuales y no se me ocurre nada que decir en contra de tus tesis, pero, con todo, lo que dices podría no ser verdadero» ${ }^{43}$.

Como conclusión diremos que el uso del término verdadero, tal y como la entiende Richard Rorty, consiste simplemente en «la mejor idea que tenemos en la actualidad sobre cómo explicar lo que está ocurriendo» ${ }^{44}$ o como «la sustantivación de un adjetivo aprobatorio» ${ }^{45}$. Después de haber ofrecido una justificación, nosotros podemos decir: «Es por esto por lo que considero que mi afirmación (assertion) es ver-

\footnotetext{
${ }^{39}$ Rorty recoge esta idea de Putnam. Cfr. Rorty, R., «La verdad sin correspondencia» en ¿Esperanza o conocimiento?, pp. 36-37. Ver también Rorty, R., «La filosofía como ciencia, como metáfora y como política» en Essays on Heidegger and Others (Philosophical Papers, Volume 2), Cambridge University Press, Cambridge 1991. Traducción al español: Ensayos sobre Heidegger y otros pensadores contemporáneos, Paidós, Barcelona 1993, p. 28. Cito como EHO.

${ }^{40}$ Rorty, R., «La verdad sin correspondencia» en ¿Esperanza o conocimiento?, p. 40.

${ }^{41}$ Rorty, R., "¿Solidaridad u objetividad?» en ORT., p. 42. (Cursivas del autor).

${ }^{42}$ Rorty, R., «¿Es la verdad una meta de la investigación?» en $T P$, p. 57.

43 Rorty, R., «Hilary Putnam y la amenaza del relativismo» en TP, p. 85.

${ }^{44}$ Rorty, R., PMN, p. 347.

${ }^{45}$ Rorty, R., «Feminismo y pragmatismo» en TP, p. 273.
} 
dadera» $\mathrm{O}$ «Esto es por lo que mi afirmación es verdadera» ${ }^{46}$; ahora bien, esto no indica que se halla alcanzado algún tipo de meta final o última para la investigación y, por consiguiente, que nos podamos situar más allá de lo que está justificado: «Decir esto es ofrecer sólo una meta que continuamente retrocede ante nosotros, una meta que se desvanece para siempre y sin remedio cuando nos movemos ${ }^{47}$. La verdad, entendida en estos términos, no es más que lo que queda después de una conversación entre colegas, en la que hemos salvado toda objeción. Lo verdadero es «el resultado de una comunicación no distorsionada, el punto de vista que resulte triunfante en un combate libre y abierto, sea ello lo que fuere» ${ }^{48}$. Pero «ningún método puede hacernos saber cuándo hemos alcanzado la verdad o si estamos más cerca de ésta que antes ${ }^{49}$. Y si alguien se presenta delante de nosotros con ideas contrarias, el etnocentrismo se congratula diciendo que «lo que hay que hacer es sonreír, hacer el mejor trato posible y, tras un esforzado regateo, retirarnos a nuestro club. Allí nos sentiremos reconfortados por la compañía de nuestros partenaires morales» ${ }^{50}$.

\section{4. ¿Es consistente el uso neopragmatista de la verdad?}

La crítica que Rorty hace a la noción de verdad como correspondencia, la falacia de la teoría de «la verdad como correspondencia» comienza cuando se piensa que la relación entre lenguaje y realidad es fragmentaria ("como la relación entre piedras individuales y rocas individuales») $)^{51}$. Ahora bien, el hecho de que esta noción de verdad como correspondencia no funcione, ¿legitima y hace plausible el uso que Rorty hace de la verdad en su sentido neopragmatista? A partir de la concepción neopragmatista de la verdad se puede afirmar que el desplazamiento que el neopragmatismo lleva a cabo, desde el abandono de la noción de verdad como correspondencia al uso neopragmatista de la verdad, no puede justificarse, cuando se demuestra que el uso que Rorty hace de la verdad se apoya en la noción «clásica» de verdad.

\footnotetext{
${ }^{46}$ Rorty, R., «Response to Jürgen Habermas» en Rorty and His Critics, p. 56.

${ }^{47}$ Rorty, R., «¿Es la verdad una meta de la investigación?» en TP, p. 57.

${ }^{48}$ Rorty, R., «La contingencia de la comunidad liberal» en CIS, p. 86. Esto implica un desplazamiento del ámbito de la epistemología al ámbito de la política. Cfr. Sleat, M., "On the Relationship between Truth and Liberal Politics» en Inquiry, vol. 50, n. 3, (2007), pp. 288-305.

${ }^{49}$ Rorty, R., "Pragmatismo, relativismo e irracionalismo» en CP, p. 247. (Cursivas del autor).

${ }^{50}$ Rorty, R., «Sobre el etnocentrismo» en $O R T$, p. 283.

${ }^{51}$ Rorty, R., «Pragmatismo, Davidson y la verdad» en $O R T$, p. 198.
} 
Rorty no tiene dudas en aceptar el sentido común de mundo, como el referente asignable a la gran mayoría de nuestras creencias. Las estrellas, las mesas o las personas constituyen el mundo en la medida en que son los referentes, cuya inexistencia, nadie - excepto el realista científico de turno- cuestionaría ${ }^{52}$. En este sentido, el neopragmatismo no tendría dudas en afirmar que es el mundo, en cierto sentido, el que decide y determina la verdad de las cosas. Pero, ¿̨cómo determina el mundo la verdad? Rorty responde: «La determinación acaba por ser tan solo el hecho de que nuestra creencia en la blancura de la nieve es blanca es debido a que la nieve es blanca y de que nuestras creencias acerca de las estrellas son verdaderas debido a que las distribuimos en constelaciones, etc. ${ }^{53}$.

Si esta concepción de Tarski es la teoría de la verdad como correspondencia, entonces, ésta es inobjetable para cualquiera, o por lo menos, para Rorty lo es ${ }^{54}$. Si embargo, Rorty cree que los que apoyan la controvertida teoría filosófica de la «verdad-correspondencia» quieren decir mucho más, pues, "este sentido trivial de «verdad» como «una correspondencia con la realidad» y como algo que «depende de una realidad independiente de nuestro conocimiento" no contenta al realista ${ }^{55}$. Por esta razón, Rorty ha especificado que la noción de verdad como correspondencia no explica nada, cuando se considera como una correspondencia fragmentaria entre lenguaje y realidad, es decir, «una cuestión de contacto de capacidades integrantes discretas con masas de realidad discretas» ${ }^{56}$.

Como se puede apreciar, la crítica de Rorty se dirige a la concepción de la verdad que el realista obsesivo del siglo XX sostiene, una teoría de la verdad que se inserta en el debate entre realistas y antirrealistas. De hecho, el pensador norteamericano dice así: «Pues supongamos que disponemos de una teoría por la que el tercer ojo, el de la mente, tiene o no tiene una clara visión de la naturale-

${ }^{52}$ Cfr. Rorty, R., «El mundo felizmente perdido» en $C P$, p. 74.

${ }^{53}$ Rorty, R., "El mundo felizmente perdido» en CP., p. 74. Como se sabe, este uso de la relación entre el mundo y nuestras creencias procede del filósofo analítico Alfred Tarski en «The Semantic Conception of Truth and the Foundations of Semantics», Philosophy and Phenomenological, IV (1944), pp. 341-375. Traducción al español: «La concepción semántica de la verdad y los fundamentos de la semántica» en M. Bunge (ed.), Antología semántica, Nueva visión, Buenos Aires 1960, pp. 111-157.

${ }^{54}$ Rorty no está indicando que la teoría semántica de Tarski es trivial. Ver nota al pie no 13 de «El mundo felizmente perdido» en $C P$, p. 75.

${ }^{55}$ Rorty, R., «El mundo felizmente perdido» en CP, p. 74. (Comillas del autor).

${ }^{56}$ Rorty, R., «Pragmatismo, Davidson y la verdad» en $O R T$, p. 198. 
za de las cosas, el tipo de teoría que encontramos, pongamos por caso, en algunas partes de los Segundos Analíticos de Aristóteles [...]. Si dejamos de concebir el conocimiento como resultado de la manipulación de Vorstellungen, creo que podemos restituir la sencilla noción aristotélica de verdad como una correspondencia con la realidad de la que tenemos clara conciencia, pues entonces demostrará ser la indiscutible trivialidad que de hecho es ${ }^{57}$.

Esta idea es interesante, porque con estas palabras, en principio, Richard Rorty todavía cree que es posible restituir «la sencilla noción aristotélica de verdad como una correspondencia con la realidad», pues sólo dice algo que es trivial. Al menos, el Americano no está en contra de la intuición de que hablamos sobre cosas, sobre personas y sobre el mundo. Y si Rorty no está en contra de que nuestro lenguaje describe el mundo, aún cuando estas descripciones sólo pueden ser más o menos útiles, ¿̇e podría afirmar que el neopragmatismo, a través de su tratamiento pragmático de la verdad, se hace cargo de cierta noción de verdad?

Rorty no está en contra de la noción aristotélica de verdad, a pesar de su trivialidad, ya que esta comprensión de la verdad viene a decir que cuando se emite un juicio asertivo o apofántico, es decir, cuando se describe o manifiesta (apophainesthai) cómo están las cosas, se está poniendo en relación dos términos que, en función de lo que se predica o se dice del sujeto, se da la propiedad de ser verdadero o de ser falso. Así lo expresa Aristóteles: «... verdadero o falso, y eso es en las cosas el estar juntas o separadas, de suerte que estará en lo verdadero el que piensa que lo separado está separado y que lo junto está junto, y estará en lo falso aquel cuyo pensamiento está en contradicción con las cosas» ${ }^{58}$. Pero Platón dijo también que un discurso es verdadero, porque dice "cómo son las cosas» y un discurso es falso cuando «dice cosas diferentes de las que son», o sea, «dice lo que no es, como si fuera " 59 . Esta es la noción "clásica» de verdad, pues fue elaborada por los filósofos más importantes de la Antigüedad clásica, Platón y Aristóteles ${ }^{60}$.

${ }^{57}$ Rorty, R., «El mundo felizmente perdido» en CP., p. 76.

${ }^{58}$ Aristóteles, Metafísica IX, 10, 1051b 2-6. Utilizo la traducción al español de la edición trilingüe de García Yebra, Gredos, Madrid 1982.

${ }^{59}$ Platón, El sofista, 263b. Utilizo la traducción al español de N. L. Cordero, en Platón, Diálogos, vol. V, Gredos, Madrid 1988.

${ }^{60}$ Cfr. Platón, El sofista, 262 a - 263 e; Aristóteles, Sobre la interpretación, 1-4; Metafisica IX, 10, 1051b 2-9. VI, 4, 1027b 18-28. 
Pero es que, además, no puede ser de otra manera, pues Rorty está presuponiendo de manera constante esta noción "clásica» de verdad, en el sentido de que aquello que él dice es verdadero y no lo considera falso. Si Rorty aceptara que tanto su crítica desconstructiva de la noción de verdad como correspondencia, como su visión particular sobre el tratamiento de la verdad no fuera verdadero, ¿qué sentido puede tener toda su elaboración filosófica? A pesar de que la obra temprana de Rorty hace hincapié en que su propuesta neopragmatista no puede apelar a la verdad ${ }^{61}$, el propio Rorty ha reconocido lo siguiente:

«Confieso que todavía a las alturas de 1986 hacía la desafortunada distinción entre «demostrar que los filósofos anteriores estaban equivocados» $\mathrm{y}$ «ofrecer redescripciones en un lenguaje alternativo», en lugar de decir de un solo golpe que afirmar que los antepasados de uno usaban un mal lenguaje es lo mismo que afirmar que estaban cometiendo un cierto tipo de error. No importa qué bobadas haya podido decir yo en el pasado. [...] Tampoco tengo reparos en afirmar que, cuando avanzo opiniones filosóficas de alcance, lo que tengo son "pretensiones de verdad» y no me limito a recomendar que se hable de un modo diferente» ${ }^{62}$.

El argumento desconstructivista que Rorty lanza contra los supuestos de la filosofía tradicional y su tratamiento de la verdad asume, de forma inequívoca, que los filósofos anteriores cometieron algún tipo de error; de lo contrario, sus críticas no serían efectivas. El hecho es que Rorty pretende desvincularse de una tradición que, por el motivo que fuese (ya sea porque se equivocaron, ya sea porque presenten cuestiones fútiles y es preciso cambiar de tema), está en el error. Según esto, el error de los filósofos anteriores ha sido el siguiente: pensar que es posible hablar de lo verdadero y de lo falso en términos de correspondencia, cuando esto ha demostrado ser un fracaso. Ya no es posible hablar de la verdad, según Rorty, en términos de correspondencia, sino de justificación o asertabilidad garantizada.

Precisamente, son los autores más sistemáticos y rigurosos de la filosofía analítica los que han permitido entender que la noción de «mundo», que el verdade-

${ }^{61}$ Rorty no puede admitir que la noción de verdad como correspondencia es falsa, es decir, no se corresponde con la realidad, a que el neopragmatismo propone simplemente otra forma de hablar más brillante.

${ }^{62}$ Rorty, R., nota al pie 16 en «Charles Taylor en torno a la verdad» en TP, p. 125. (Comillas del autor). 
ro creyente realista sostiene, tiene más de obsesión que de intuición. El mundo como «cosa-en-sí» no funciona porque no se puede dar sentido a la idea de mundo como «causa inefable de nuestra sensibilidad». Pero tampoco puede mantenerse una concepción de la realidad como algo que mantiene una relación con el lenguaje o el pensamiento de tipo "fragmentario», pues el lenguaje penetra tan profundamente en lo que nosotros llamamos «realidad», que la idea de vernos a nosotros mismos como cartógrafos de algo, es un imposible. Por eso, Rorty ha demostrado que la noción de mundo del «realista obsesivo» y que la verdad como correspondencia entre lenguaje y hecho, no puede hacerse efectiva.

Ahora bien, ¿en qué sentido podemos afirmar que el uso neopragmatista de la verdad es inconsistente? Decimos que la visión neopragmatista de la verdad asume la noción "clásica» de verdad en el siguiente sentido.

El juicio del neopragmatismo, que asevera que la verdad es solamente:

1. un uso como aval o de aprobación y apoyo;

2. un uso precautorio o de advertencia, como cuando decimos que la creencia $S$ está perfectamente justificada, pero quizás no es verdadera;

3. un uso desentrecomillador como cuando decimos: "La nieve es blanca» es verdadero si y sólo si la nieve es blanca ${ }^{63}$;

o también:

4. aquello cuya creencia resulta beneficiosa ${ }^{64}$;

5. aquello que se reemplaza por la justificación ${ }^{65}$,

es verdadero, porque $1,2,3,4$, y 5 se conforman a la realidad descrita por el neopragmatismo. Es decir, en las proposiciones 1, 2, 3, 4 y 5, a través de los datos que posee (es decir, de la imposibilidad de entender la realidad como Realidad-en-Sí, como una realidad que se descompone en trozos, llamados «hechos»), considera que 1, 2, 3, 4 y 5 «dice cómo son las cosas» («piensa que lo separado

${ }^{63}$ Rorty, R., «Pragmatismo, Davidson y la verdad» en $O R T$, p. 175.

${ }^{64}$ Rorty, R., PMN, pp. 19. 166; «Pragmatismo, relativismo e irracionalismo» en CP, p. 243; «¿Solidaridad u objetividad?» en $O R T$, p. 41.

${ }^{65}$ Rorty, R., «Introducción» en TP, pp. 13-14. 
está separado y que lo junto está junto»). Y el juicio que asevera «cómo son las cosas» tiene la propiedad de ser verdadero.

De manera similar, Rorty puede sostener que el juicio de la filosofía tradicional, que asevera que la verdad es:

(a) correspondencia entre el pensamiento o el lenguaje y la Realidad-tal-comoes-en-Sí-misma, como una correspondencia entre los elementos del lenguaje y realidad en sus «hechos»,

es falso, porque (a) no dice "cómo son las cosas», sino «dice cosas diferentes de las que son», o sea, «dice lo que no es, como si fuera» («su pensamiento está en contradicción con las cosas»). Y el juicio que no asevera "cómo son las cosas» tiene la propiedad de ser falso ${ }^{66}$.

En definitiva, Rorty está asumiendo una teoría filosófica de la verdad, esto es, la noción "clásica» de verdad, a pesar de que el neopragmatismo defiende una posición deflacionista o eliminacionista de la verdad. Rorty no puede escapar a la noción "clásica» de verdad, pues ésta es una noción básica, esencial al pensamiento, ya que, como ha dicho Donald Davidson (y Rorty estaría de acuerdo), «sin la idea de verdad no seríamos personas que piensan, ni podríamos entender qué es para alguien el ser una persona que piensa ${ }^{67}$. En el mismo momento en el que se hace una aserción asertiva o apofántica (por ejemplo: «lo verdadero es «el resultado de una comunicación no distorsionada, el punto de vista que resulte triunfante en un combate libre y abierto, sea ello lo que fuere»m ${ }^{68}$ ) ésta tiene la propiedad de ser verdadera o de ser falsa.

\section{Conclusión}

Como conclusión, se puede constatar que la concepción neopragmatista de la verdad puede adolecer de inconsistente, porque ésta se apoya y asume la noción

\footnotetext{
${ }^{66}$ Se está aplicando la noción «clásica» de verdad teorizada tanto por Platón como por Aristóteles. Cfr. Platón, El sofista, 263b; Aristóteles, Metafísica IX, 10, 1051b 2-6.

${ }^{67}$ Davidson, D., "Truth Rehabilitated» en Rorty and His Critics, p. 72.

${ }^{68}$ Rorty, R., "La contingencia de la comunidad liberal» en CIS, p. 86.
} 
«clásica» de verdad, cuando el propio Rorty ha reconocido que él no presenta ninguna teoría filosófica de la verdad. Y si se comprende que la noción "clásica» de verdad no viene sino a expresar una propiedad que, necesariamente, tiene o no tiene los enunciados asertivos (aquellos que describen), se puede afirmar consecuentemente:

Que el neopragmatismo no puede concluir diciendo que la verdad es únicamente

1. un uso como aval o de aprobación y apoyo;

2. un uso precautorio o de advertencia, como cuando decimos que la creencia $S$ está perfectamente justificada, pero quizás no es verdadera;

3. un uso desentrecomillador como cuando decimos: «La nieve es blanca» es verdadero si y sólo si la nieve es blanca;

4. aquello cuya creencia resulta beneficiosa.

5. aquello que se reemplaza por la justificación,

cuando 1, 2, 3, 4, y 5 asume la noción «clásica» de verdad, es decir, cuando $1,2,3,4$, y 5 «dice cómo son las cosas», o dicho de otro modo, "piensa que lo separado está separado y que lo junto está junto».

\section{Bibliografía}

\section{Obras de Richard Rorty}

- (1982). Consequences of Pragmatism (Essays:1972-1980). University of Minnesota Press, Minneapolis. Traducción al español: Consecuencias del pragmatismo, Tecnos, Madrid 1996.

- (1989). Contingency, Irony and Solidarity, Cambridge University Press, New York. Traducción al español: Contingencia, ironía y solidaridad, Paidós, Barcelona 1991.

- (1991). Essays on Heidegger and Others (Philosophical Papers, Volume 2), Cambridge University Press, Cambridge. Traducción al español: Ensayos sobre Heidegger y otros pensadores contemporáneos, Paidós, Barcelona 1993. 
- (1991). Objectivity Relativism, and Truth (Philosophical Papers, Volume 1), Cambridge University Press, Cambridge. Traducción al español: Objetividad, relativismo y verdad, Paidós, Barcelona 1996.

- (1999). Philosophy and Social Hope, Penguin Books, London. Traducción al español: ¿Esperanza o conocimiento? Una introducción al pragmatismo, FCE, Buenos Aires 1997.

- (1979). Philosophy and the Mirror of Nature, Princeton University Press, New Jersey. Traducción al español: La filosofía y el espejo de la naturaleza, Cátedra, Madrid 1983.

- (2000). «Response to Robert Brandom» en Rorty and His Critics, Blackwell, Oxford, pp. 183-190.

- (1998). Truth and Progress (Philosophical Papers, Volume 3), Cambridge University Press, Cambridge. Traducción al español: Verdad y progreso (Escritos filosóficos 3), Paidós, Barcelona 2000.

- (2007). «Universalidad y verdad» en Rorty and His Critics, pp. 1-30. Traducción al español: «Universalidad y verdad» en Rorty, R./Habermas, J., Sobre la verdad: ¿validez universal o justificación?, Amorrortu, Buenos Aires 2007.

- (2007). What is the Use of Truth?, Columbia University Press, New York.

\section{Otras fuentes}

Aristóteles (1982). Metafísica. Traducción al español de la edición trilingüe de García Yebra, Gredos, Madrid.

Bilgrami, A. (2000). «Is Truth a Goal of Inquiry?: Rorty and Davidson on Truth» en Rorty and His Critics, Blackwell, Oxford, pp. 242-262.

KALPOKAS, D. (2005). Richard Rorty y la superación pragmatista de la epistemología, ediciones del Signo, Buenos Aires.

Platón (1998). El sofista. Traducción al español de N. L. Cordero, en Platón, Diálogos, vol. V, Gredos, Madrid. 
Putnam H. (1990). Realism with a Human Face, Harvard University Press, Cambridge (Mass.).

Sleat, M. (2007). «On the Relationship between Truth and Liberal Politics» en Inquiry, vol. 50, n. 3, pp. 288-305.

TARSKI, A. (1944). «The Semantic Conception of Truth and the Foundations of Semantics», Philosophy and Phenomenological, IV (1944), pp. 341-375. Traducción al español: «La concepción semántica de la verdad y los fundamentos de la semántica» en M. Bunge (ed.), Antología semántica, Nueva visión, Buenos Aires 1960, pp. 111-157.

Recibido: 27/04/2010

Aceptado: 26/10/2010 
